\title{
Dopaminergic Mechanisms Underlying Normal Variation in Trait Anxiety
}

\author{
(1)Anne S. Berry, ${ }^{1,2}$ Robert L. White III, ${ }^{2}$ Daniella J. Furman, ${ }^{2}$ Jenna R. Naskolnakorn, ${ }^{2}$ Vyoma D. Shah, ${ }^{1,2}$ \\ (D)Mark D’Esposito, ${ }^{2}$ and DWilliam J. Jagust ${ }^{1,2}$ \\ ${ }^{1}$ Lawrence Berkeley National Laboratory, Berkeley, California 94720, and ${ }^{2}$ Helen Wills Neuroscience Institute, University of California Berkeley, Berkeley, \\ California 94720
}

Trait anxiety has been associated with altered activity within corticolimbic pathways connecting the amygdala and rostral anterior cingulate cortex (rACC), which receive rich dopaminergic input. Though the popular culture uses the term "chemical imbalance" to describe the pathophysiology of psychiatric conditions such as anxiety disorders, we know little about how individual differences in human dopamine neurochemistry are related to variation in anxiety and activity within corticolimbic circuits. We addressed this issue by examining interindividual variability in dopamine release at rest using $\left[{ }^{11} \mathrm{C}\right]$ raclopride positron emission tomography (PET), functional connectivity between amygdala and rACC using resting-state functional magnetic resonance imaging (fMRI), and trait anxiety measures in healthy adult male and female humans. To measure endogenous dopamine release, we collected two [ ${ }^{11} \mathrm{C}$ ]raclopride PET scans per participant. We contrasted baseline $\left[{ }^{11} \mathrm{C}\right]$ raclopride $\mathrm{D} 2 / 3$ receptor binding and D2/3 receptor binding following oral methylphenidate administration. Methylphenidate blocks the dopamine transporter, which increases extracellular dopamine and leads to reduced $\left[{ }^{11} \mathrm{C}\right]$ raclopride D2/3 receptor binding via competitive displacement. We found that individuals with higher dopamine release in the amygdala and rACC self-reported lower trait anxiety. Lower trait anxiety was also associated with reduced rACC-amygdala functional connectivity at baseline. Further, functional connectivity showed a modest negative relationship with dopamine release such that reduced rACC-amygdala functional connectivity was accompanied by higher levels of dopamine release in these regions. Together, these findings contribute to hypodopaminergic models of anxiety and support the utility of combining fMRI and PET measures of neurochemical function to advance our understanding of basic affective processes in humans.

Key words: amygdala; anterior cingulate; anxiety; dopamine; fMRI; raclopride

Significance Statement

It is common wisdom that individuals vary in their baseline levels of anxiety. We all have a friend or colleague we know to be more "tightly wound" than others, or, perhaps, we are the ones marveling at others' ability to "just go with the flow." Although such observations about individual differences within nonclinical populations are commonplace, the neural mechanisms underlying normal variation in trait anxiety have not been established. Using multimodal brain imaging in humans, this study takes initial steps in linking intrinsic measures of neuromodulator release and functional connectivity within regions implicated in anxiety disorders. Our findings suggest that in healthy adults, higher levels of trait anxiety may arise, at least in part, from reduced dopamine neurotransmission.

\section{Introduction}

Pharmacological interventions for anxiety primarily target serotonergic and GABAergic neurotransmitter systems. However,

\footnotetext{
Received Sept. 14, 2018; revised Jan. 3, 2019; accepted Jan. 29, 2019.

Author contributions: A.S.B. wrote the first draft of the paper; A.S.B., R.L.W., D.J.F., J.R.N., V.D.S., M.D., and W.J.J. edited the paper; M.D. and W.J.J. designed research; R.L.W., D.J.F., J.R.N., and W.J.J. performed research; A.S.B., R.L.W., D.J.F., J.R.N., and V.D.S. analyzed data; A.S.B. wrote the paper.

This work was funded by R01 DA034685 (M.D.), R01 AG044292 (W.J.J.), K99 AG058748 (A.S.B.), and an Alzheimer's Association Research Fellowship (A.S.B.); The fMRI was conducted at the Henry H. Wheeler, Jr. Brain Imaging Center which is supported by the National Science Foundation through their Major Research Instrumentation Program BSC-0821855. We thank Regina Lapate for useful discussions.
}

early lines of research emphasized a role of dopamine in the pathophysiology of anxiety (Taylor et al., 1982), which recently have been reinvigorated (Kienast et al., 2008a; Dedic et al., 2018). Here, we measured self-reported trait anxiety in healthy adults, and investigated its relationships with brain dopamine function and functional connectivity within circuits implicated in anxiety

The authors declare no competing financial interests. Correspondence should be addressed to Anne Berry at anneberry@berkeley.edu. https://doi.org/10.1523/JNEUROSCI.2382-18.2019

Copyright $\odot 2019$ the authors 
regulation to probe the neural substrates of this individual difference.

Studies of patients with anxiety disorders, post-traumatic stress disorder, and depression provide a foundation for our understanding of the neural underpinnings of anxiety in humans. These studies have been integral in placing dysregulated amygdala activity at the center of anxiety models (Davidson, 2002; Shin and Liberzon, 2010; Fonzo and Etkin, 2017). What factors cause or ameliorate aberrant amygdala activity are a focus of active research. However, it is clear that functional connections with prefrontal cortex (PFC) enhance and dampen amygdala activity (Rosenkranz and Grace, 2002; Bissière et al., 2008). Rostral anterior cingulate cortex (rACC), and particularly its subgenual portion, is a primary regulator of amygdala activity (Etkin et al., 2006). Supporting this view, rACC-amygdala functional connectivity at rest (Prater et al., 2013; Brown et al., 2014) and during task performance (Prater et al., 2013; Stevens et al., 2013) reliably distinguishes people with anxiety disorders from controls. Indeed, reverse-inference search of the NeuroSynth database (Yarkoni et al., 2011) finds rACC, in addition to amygdala, as the region most strongly associated with the term "anxiety."

Accumulating evidence links amygdala and PFC dopamine with both anxiety and modulation of functional magnetic resonance imaging (fMRI) activity within these regions. Reduction in dopamine release in rodent medial PFC increases behavioral measures of anxiety (Refojo et al., 2011; Dedic et al., 2018). More generally, a link between dopamine and anxiety is suggested by the high prevalence of anxiety in Parkinson's disease (Walsh and Bennett, 2001), in which there is decline in dopaminergic input to the amygdala and PFC (Javoy-Agid and Agid, 1980; Ouchi et al., 1999) that accompanies losses of striatal terminals. Though these observations support hypodopaminergic accounts of anxiety, there is also evidence that hyperdopaminergic states produce elevated anxiety. High doses of amphetamines and cocaine, which increase extracellular dopamine, are anxiogenic (Angrist and Gershon, 1970; Volkow et al., 1994; David et al., 2001), and alter activation in rACC and amygdala (Hariri et al., 2002; Moeller et al., 2014). Indeed, $\left[{ }^{18} \mathrm{~F}\right]$ fluoro-L-DOPA imaging in healthy humans has revealed positive relationships between dopamine storage capacity in the amygdala and task-evoked activation in corticolimbic regions associated with emotional regulation (Kienast et al., 2008a). Although together these studies reveal associations between dopamine function, corticolimbic activity, and anxiety, it remains unclear to what extent these relationships exist in healthy populations and, if present, whether reduced or elevated levels of endogenous release are associated with greater anxiety.

To address this gap, we used $\left[{ }^{11} \mathrm{C}\right]$ raclopride to measure spontaneous dopamine release in vivo. $\left[{ }^{11} \mathrm{C}\right]$ raclopride, a weak competitive D2/3 receptor antagonist, is the most commonly used positron emission tomography (PET) tracer for quantifying dopamine release in humans. We compared baseline signal [nondisplaceable binding potential $\left.\left(\mathrm{BP}_{\mathrm{ND}}\right)\right]$ with $\mathrm{BP}_{\mathrm{ND}}$ following oral methylphenidate. Studies combining PET with microdialysis have validated pharmacologically-paired $\left[{ }^{11} \mathrm{C}\right]$ raclopride imaging methods for quantifying dopamine release (Breier et al., 1997; Endres et al., 1997; Tsukada et al., 1999). Whereas the relatively low affinity of $\left[{ }^{11} \mathrm{C}\right]$ raclopride for $\mathrm{D} 2 / 3$ receptors underlies its utility for quantifying dopamine release through competitive displacement, its low affinity limits signal in regions with diffuse receptor expression. In humans, D2 receptor density is low in PFC, moderate in amygdala, and highest in striatum (Kessler et al., 1993). However, despite diffuse PFC receptors, $\left[{ }^{11} \mathrm{C}\right]$ raclo- pride test-retest in ACC demonstrates high reliability (intraclass correlation $=0.84$ ) following 5 weeks, comparable to reliability in striatum (0.82-0.83; Alakurtti et al., 2015). Using $\left[{ }^{11} \mathrm{C}\right]$ raclopride, this study takes initial steps to describe relationships between individual differences in neurochemistry, correlated fMRI activity, and normal variation in trait anxiety.

\section{Materials and Methods}

\section{Participants}

Thirty participants ( $18-25$ years old, $\mathrm{M}=21.50, \mathrm{SD}=2.08,20$ female, 17 Asian, 7 White, 2 Black or African American, 2 Latino, $1>1$ race) are included in the current analyses. Participants did not have a history of neurological, psychological or psychiatric disorder, and did not smoke or take medication that affects cognition. The Institutional Review Boards at the University of California, Berkeley, and Lawrence Berkeley National Laboratory approved the study. All participants provided written consent and received monetary compensation.

Participants were recruited as part of a larger study examining relationships between dopamine function and cognitive control. The Trait component of the State-Trait Anxiety Inventory (STAI; Spielberger et al., 1983) was included in this study protocol, with a secondary aim of evaluating a role of dopamine function in trait anxiety. Before enrollment, participants underwent medical screening and physical examination by a medical doctor or nurse practitioner. Exclusion criteria included consumption of $>7$ alcoholic drinks per week, and use of psychoactive drugs within 2 weeks of enrollment or 10 times in the past year. Additionally, we tested drug and alcohol use via urine drug screening and alcohol breath test before enrollment. No participant tested positive for any psychoactive drug, and alcohol breath test confirmed alcohol concentration $<0.05 \%$. Before the PET sessions, participants underwent additional screening for self-reported drug use including screening for methylphenidate, dexmethylphenidate, dextroamphetamine, lisdexamfetamine, amphetamine, and methamphetamine.

Each participant completed fMRI sessions on separate days following the administration of placebo or drug using a double-blind study design. The present analysis uses resting-state data for only the placebo condition. STAI, fMRI, and PET sessions were performed within 9 months of one another for each participant (STAI and fMRI: $\mathrm{M}=57 \mathrm{~d}$ apart, $\mathrm{SD}=$ 36, range: $14-170$; STAI and PET: $\mathrm{M}=119 \mathrm{~d}$ apart, $\mathrm{SD}=59$, range: 43-269; fMRI and PET: $\mathrm{M}=62 \mathrm{~d}$ apart, $\mathrm{SD}=54$, range: 7-231). Five additional participants were excluded because of insufficient fMRI data quality, incomplete STAI, STAI $>2$ SD above the mean, or selective serotonin reuptake inhibitor use that was initiated after enrollment but disclosed during subsequent screening.

\section{Experimental design}

Trait anxiety, resting-state fMRI functional connectivity, and dopamine release were collected for each participant. Specific methods for data collection and analysis are detailed the following subsections.

Trait anxiety. We measured self-reported anxiety using the Trait component of the STAI (Spielberger et al., 1983). Participants responded to 20 statements regarding their typical anxiety (e.g., "I feel that difficulties are piling up so that I cannot overcome them"). Participants rated the extent to which each statement reflected their typical feelings $(1=$ almost never, $2=$ sometimes, $3=$ often, $4=$ almost always). STAI was collected during a separate neuropsychological testing session that occurred before imaging sessions. Though the time delay between sessions potentially interfered with the detection of relationships between trait anxiety and neural measures, trait anxiety measures generally show good test-retest reliability even after 2 years (Usala and Hertzog, 1991). In college-age students, Spielberger trait anxiety shows high reliability in college males and females tested up to $104 \mathrm{~d}(r=0.73-0.77)$ that surpasses stability of state measures ( $r=0.31-0.33$; Spielberger et al., 1983).

Structural MRI. T1-weighted magnetization prepared rapid gradient echo (MPRAGE) scans [repetition time $(\mathrm{TR})=2300 \mathrm{~ms}$; echo time $(\mathrm{TE})=2.98 \mathrm{~ms}$; flip angle $(\mathrm{FA})=9^{\circ}$; matrix $=240 \times 256$; field-of-view $($ FOV $)=256$; sagittal plane; voxel $=1 \times 1 \times 1 \mathrm{~mm}$; 160 slices $]$ were acquired using a Siemens 3T Trio Tim scanner with a 12-channel coil. 
MPRAGE scans were segmented using FreeSurfer v5.1 (http://surfer. nmr.mgh.harvard.edu/).

Regions-of-interest. Regions-of-interest (ROIs) for the bilateral amygdala and rACC were defined using individual subjects' FreeSurfer segmentations, and were used to probe relationships between dopamine release, functional connectivity, and trait anxiety. The entire rACC (rather than strictly the subgenual portion of rACC) and the entire amygdala (rather than strictly the basolateral portion of the amygdala) were used as ROIs because of considerations related to the relatively low binding of $\left[{ }^{11} \mathrm{C}\right]$ raclopride outside of striatum and PET spatial resolution.

For dopamine release, primary analyses were conducted using a composite ROI that comprised both bilateral amygdala and rACC. The composite ROI was used to increase statistical power, because we did not have specific hypotheses that dopamine release in amygdala or rACC would be differentially related to anxiety or functional connectivity. However, we also report correlation analyses for these regions independently so that the reader can assess the consistency of results. Parallel control analyses were conducted using a bilateral occipital cortex ROI also derived from individual participants' FreeSurfer segmentations. We did not predict relationships between trait anxiety and dopamine release or functional connectivity in this region.

The central aim of this study was to examine dopamine release in amygdala and rACC because of the exceptionally consistent literature implicating these structures in anxiety. However, we recognize that readers may be interested in comprehensive reporting of relationships between anxiety and dopamine release in subregions of the striatum as well as hippocampus (for links between hippocampus and approachavoidance behavior, see Gray and McNaughton, 2000; Bach et al., 2014; O'Neil et al., 2015; Loh et al., 2017). Analyses testing relationships between trait anxiety and dopamine release in these alternative ROIs are additionally reported here. Analyses involving resting-state fMRI connectivity between amygdala and these alternative ROIs can be accessed at: https://doi.org/10.6078/D1JM3K. Hippocampus ROIs were derived from individual participants' FreeSurfer segmentations. ROIs in dorsal caudate nucleus (DCA), dorsal putamen (DPUT), and ventral striatum (VST) were manually segmented and drawn on each participant's T1 MPRAGE as previously described (Mawlawi et al., 2001). Inter-rater reliability was high for manually drawn striatal subregions. For ROIs of five participants drawn by three raters, the Sorensen-Dice coefficient ranged from 0.80 to 0.89 .

$\left[{ }^{11} \mathrm{C}\right]$ raclopride PET acquisition. The PET tracer $\left[{ }^{11} \mathrm{C}\right]$ raclopride is a weak competitive $\mathrm{D} 2 / 3$ receptor antagonist whose signal is sensitive to the concentration of synaptic dopamine; when synaptic dopamine increases, radioligand signal decreases (Endres et al., 1997). To estimate dopamine release during rest, we collected two PET scans per subject and compared baseline $\left[{ }^{11} \mathrm{C}\right]$ raclopride signal $\left(\mathrm{BP}_{\mathrm{ND}}\right)$ with $\left[{ }^{11} \mathrm{C}\right]$ raclopride $\mathrm{BP}_{\mathrm{ND}}$ following oral methylphenidate administration. Methylphenidate blocks the dopamine transporter (Kuczenski and Segal, 1997), increasing synaptic dopamine concentration (Berry et al., 2018a, their Fig. 1d). Because methylphenidate blocks dopamine uptake rather than stimulating dopamine release (as is the case for amphetamine), this method allows for quantification of the amount of intrinsic dopamine release. Support for this interpretation is provided by Volkow et al. (2002) who showed that individual differences in the extent of methylphenidate blockade of the dopamine transporter does not explain interindividual variability in the magnitude of $\left[{ }^{11} \mathrm{C}\right]$ raclopride signal reduction following methylphenidate. These findings are consistent with the view that individual differences in $\left[{ }^{11} \mathrm{C}\right]$ raclopride binding arise from differences in the activity of dopamine-releasing neurons rather than differences in transporter blockade. Therefore, individuals with low dopaminergic neuronal activity would have smaller increases in synaptic dopamine concentrations relative to individuals with high activity. Here, participants underwent PET scanning under passive conditions and were not actively engaged in a cognitive task. This measure of spontaneous, intrinsic dopamine release mirrors conditions during which intrinsic fMRI functional connectivity measures were acquired.

$\left[{ }^{11} \mathrm{C}\right]$ raclopride was synthesized at Lawrence Berkeley National Laboratory. To measure baseline $\mathrm{D} 2 / 3$ receptor occupancy, participants in- gested a placebo pill $\sim 1 \mathrm{~h}$ before $\left[{ }^{11} \mathrm{C}\right]$ raclopride Scan 1 . Consistent with previous protocols, the placebo scan was always performed first (Volkow et al., 1994). Therefore, while the research participant was blind to the PET drug condition, the experimenter was not. To measure dopamine release, participants ingested $30 \mathrm{mg}(\mathrm{M} \pm \mathrm{SD} \mathrm{mg} / \mathrm{kg}: 0.47 \pm 0.07)$ of methylphenidate $\sim 1$ h before $\left[{ }^{11} \mathrm{C}\right]$ raclopride Scan 2 . Our pilot testing determined that the $30 \mathrm{mg}$ pill produced a percentage reduction in $\left[{ }^{11} \mathrm{C}\right]$ raclopride signal in striatum within the range of signal reduction in $\left[{ }^{11} \mathrm{C}\right]$ raclopride $\mathrm{BP}_{\mathrm{ND}}$ associated with cognitive task performance: $5.3-$ 10.2\% (Monchi et al., 2006; Jonasson et al., 2014). Scans were conducted on the same day, $2 \mathrm{~h}$ apart. For both acquisitions, participants were injected with $\sim 10 \mathrm{mCi}$ of $\left[{ }^{11} \mathrm{C}\right]$ raclopride as a bolus in an antecubital vein. Specific activity (SA) and dose were not different for $\left[{ }^{11} \mathrm{C}\right]$ raclopride Scan $1(\mathrm{M} \pm \mathrm{SD} ; \mathrm{SA}=5184.77 \pm 1257.64 \mathrm{Ci} / \mathrm{mmol}$, dose $=9.84 \pm$ $0.08 \mathrm{mCi})$ and $\left[{ }^{11} \mathrm{C}\right]$ raclopride Scan $2(\mathrm{SA}=5159.37 \pm 1569.81 \mathrm{Ci} /$ $\mathrm{mmol}$, dose $=9.84 \pm 0.09 \mathrm{mCi}$ ) as assessed by paired $t$ tests (SA: $t_{(29)}=$ $0.11, p=0.91$; dose: $\left.t_{(29)}=0.15, p=0.88\right)$. Dynamic acquisition data were obtained in 3D list mode over $60 \mathrm{~min}$ and binned as 19 frames total: $5 \times 1,3 \times 2,3 \times 3$, and $8 \times 5 \mathrm{~min}$. Data were reconstructed using an ordered subset expectation maximization algorithm with weighted attenuation, corrected for scatter, and smoothed with a $4 \mathrm{~mm}$ full-width at half-maximum (FWHM) kernel.

PET preprocessing and data analysis. PET data were preprocessed using SPM8 software (Friston et al., 2007). To correct for motion between frames, images were realigned to the middle frame. The first five images were summed before realignment to improve realignment accuracy, as these early images have relatively low signal contrast. Structural images were coregistered to PET images using the mean image of frames corresponding to the first $20 \mathrm{~min}$ of acquisition as a target.

Graphical analysis was performed using a basis function version of the simplified reference tissue model analysis (SRTM; Gunn et al., 1997) with posterior cerebellar gray matter used as the reference region. Cerebellar gray matter was used as the reference region because this region shows very little tracer uptake, and has an extremely low density of dopamine receptors and metabolites relative to striatum (Hall et al., 1994). The most anterior $1 / 4$ of cerebellar gray was removed from the reference region to limit contamination of signal from the substantia nigra and ventral tegmental area. Exclusion of the anterior portion of the cerebellar gray has been reported previously (Dang et al., 2017), and was performed by manually removing the anterior $1 / 4$ of coronal slices from individual participants' native space cerebellar gray FreeSurfer segmentation using Mango software (http://ric.uthscsa.edu/mango/). Cerebellar $\left[{ }^{11} \mathrm{C}\right] \mathrm{raclo}-$ pride signal is not altered following oral methylphenidate administration (Volkow et al., 2002; Berry et al., 2018b).

The time-activity curve of the brain region of interest is described relative to the reference region. This analysis assumes the reference region has no specific binding and that both regions have the same level of non-displaceable binding. The SRTM analysis was performed using inhouse software and MATLAB v8.2. SRTM analysis was used to determine $\mathrm{BP}_{\mathrm{ND}}$, which can be defined as follows:

$$
B P_{\mathrm{ND}}=f_{\mathrm{ND}} \times \mathrm{B}_{\mathrm{avail}} / K_{\mathrm{D}}
$$

where $\mathrm{B}_{\text {avail }}$ is the concentration of $\mathrm{D} 2 / 3$ receptors, $K_{\mathrm{D}}$ is the inverse of the affinity of the radiotracer for $\mathrm{D} 2 / 3$ receptors, and $f_{\mathrm{ND}}$ is the free fraction of the ligand in the non-displaceable tissue compartment. A $\mathrm{BP}_{\mathrm{ND}}$ voxelwise map was generated for each participant for each $\left[{ }^{11} \mathrm{C}\right] \mathrm{ra}-$ clopride scan. $\left[{ }^{11} \mathrm{C}\right]$ raclopride $\mathrm{BP}_{\mathrm{ND}}$ was measured for each $\mathrm{ROI}$ for Scans 1 and 2 (average of voxels within ROIs) and compared using paired $t$ tests with effect size calculated using $d z$. We confirmed that calculating $\mathrm{BP}_{\mathrm{ND}}$ on a voxel-level basis generated similar results to $\mathrm{BP}_{\mathrm{ND}}$ calculated on a ROI-level basis, and did not affect our main conclusions. Cronbach's $\alpha$ for voxel-level and ROI-level $\mathrm{BP}_{\mathrm{ND}}$ ranged from 0.94 to 0.96 for composite, amygdala and rACC ROIs (SPSS v25). Endogenous dopamine release was calculated as the percentage change in $\mathrm{BP}_{\mathrm{ND}}$ from Scan 1 to Scan 2 [(placebo $\left[{ }^{11} \mathrm{C}\right]$ raclopride-methylphenidate $\left[{ }^{11} \mathrm{C}\right]$ raclopride)/placebo $\left[{ }^{11} \mathrm{C}\right]$ raclopride].

$f M R I$ data acquisition. Functional images were acquired using $\mathrm{T} 2{ }^{*}$ weighted echo planar imaging (EPI) with 36 interleaved slices (TR $=2 \mathrm{~s}$, 
$\mathrm{TE}=24 \mathrm{~ms}, \mathrm{FA}=65^{\circ}$, matrix $=64 \times 64, \mathrm{FOV}=192 \mathrm{~mm} ; 180$ volumes; axial; voxels $=3 \times 3 \times 3 \mathrm{~mm}$ ). Two dummy scans were acquired before acquisition. During resting-state fMRI acquisition, a white fixation cross on a black background was displayed in the center of the screen. Participants were asked to remain awake with their eyes open and focused on the cross.

Participants were administered a placebo pill before the fMRI. To test the possible influence of drug expectancy effects on fMRI data, participants filled out visual analog scales indicating the relative presence or absence of the following anxiety, mood and physical states: anxious, happy, sad, nauseous, drowsy, jittery, fatigued, and dizzy. The scales were administered at four time points (before placebo administration, before the fMRI, immediately after the fMRI, and at the end of the experimental session before going home). At the end of the fMRI session, participants were asked to guess whether they had completed a placebo or a drug session.

fMRI preprocessing and data analysis. Anatomical images and FreeSurfer segmentations were coregistered to each session's EPI data and nonlinearly warped to the MNI152 template using Analysis and Visualization of Functional Magnetic Resonance Neuroimages (AFNI) software (https://afni.nimh.nih.gov/). These segmentations were used to derive the white matter, gray matter, and lateral ventricle masks used during fMRI preprocessing, as well as to generate seed regions for the functional connectivity analyses.

Preprocessing was performed with AFNI software. The first three functional volumes were excluded to ensure steady-state magnetization. Raw time series data were despiked with the AFNI program 3dDespike. Images were then corrected for differences in slice acquisition timing using quintic interpolation. Volume registration to the functional volume with the lowest computed signal outlier fraction and nonlinear spatial warping to the MNI template were applied in a single step to limit instances of data interpolation. Removal of nuisance signals, volume censoring ("scrubbing"), and bandpass filtering $(0.01 \mathrm{~Hz}<f<0.1 \mathrm{~Hz})$ were performed in a single linear regression using AFNI's 3dTproject function. Nuisance signals included six motion parameters derived from volume registration along with their first-order derivatives, local white matter signal, time series associated with three principal components of lateral ventricle signal (aCompCor), and 0th-third order polynomial trends. Framewise motion was calculated as the derivative of the Euclidian norm of the 6 motion parameters calculated from volume registration. Motion scrubbing was performed as follows. Volumes with $>0.3$ $\mathrm{mm}$ motion were censored along with the volumes that immediately preceded them. Volumes were also flagged as contaminated when $>15 \%$ of voxels within the brain were temporal outliers, as defined by the AFNI program 3dToutcount. Across all subjects, the combination of these masks censored $4.23 \pm 8.54$ frames per subject (range $0-35$ ). Residual data were smoothed with a $5 \mathrm{~mm}$ FWHM Gaussian kernel within an anatomically-defined gray matter mask to avoid blurring with adjacent white matter and CSF.

Functional connectivity was measured using $z$-transformed Pearson correlation coefficients between bilateral amygdala and bilateral rACC (ROI-to-ROI analysis). Control analyses were conducted using ROI-toROI functional connectivity between bilateral amygdala and bilateral occipital cortex. Group-level voxelwise functional connectivity maps were generated for visualization purposes and exploratory analyses with bilateral amygdala as the seed region (details reported in Statistical analyses).

\section{Statistical analyses}

Primary statistical analyses tested correlations among STAI, dopamine release (bilateral amygdala and rACC composite ROI), and amygdalarACC functional connectivity (ROI-to-ROI connectivity). Additional analyses tested correlations between dopamine release and STAI for occipital cortex, striatal subregions, and hippocampus. We obtained skipped Pearson correlation coefficients using the Robust Correlation Toolbox in MATLAB (Pernet et al., 2012) to limit the influence of outliers and data heteroscedasticity. Correlations were considered significant if the 95\% confidence interval (CI) did not include zero. Shapiro-Wilk testing confirmed variables were normally distributed (all $\mathrm{W}>0.96$ ).
When relevant, we report tests of equality of two correlations (http://quantpsy.org).

We report results from exploratory voxelwise analyses of resting-state data. The thresholding for the group map was performed using an initial cluster forming threshold of $p<0.001$. An additional minimum cluster extent threshold was applied using 3DClustSim in AFNI (https://afni. nimh.nih.gov/; cluster level threshold $p<0.05, k>633)$. AFNI's $3 \mathrm{dFWHMx}$ was applied to group-level $\beta$ maps to estimate the spatial autocorrelation using a mixed-model function. This extent thresholding method accounts for spatial correlations of voxels and does not make assumptions about data distribution and smoothness. Further, we conducted exploratory voxelwise regression analyses in SPM12. Individual functional connectivity maps were submitted to two second-level regression analyses with trait anxiety and amygdala dopamine release entered as a regressor.

\section{Results}

\section{Trait anxiety}

Mean trait anxiety was $35.30 \pm 6.91$ (range 22-50). In our sample, we found no evidence of differences in trait anxiety between male and female participants (independent $t$ test: $t_{(28)}<1, p=$ 0.58 ), and no evidence of differences in trait anxiety between Asian and non-Asian participants [independent $t$ test between Asian $(n=17)$ vs the rest of the sample $(n=13) t_{(28)}<1, p=$ 0.87]. As such, correlation analyses were performed across all participants to preserve power.

\section{Dopamine release}

Methylphenidate reduced $\left[{ }^{11} \mathrm{C}\right]$ raclopride $\mathrm{BP}_{\mathrm{ND}}$ relative to placebo (composite ROI: paired $t_{(29)}=2.26, p=0.03, d z=0.38$; Fig. $1)$. Percentage change in $\mathrm{BP}_{\mathrm{ND}}$ was $2.29 \pm 5.64(\mathrm{M} \pm \mathrm{SD})$ in the composite ROI, $2.10 \pm 5.63$ in amygdala, and $2.10 \pm 8.87$ in rACC. We did not detect changes in $\left[{ }^{11} \mathrm{C}\right]$ raclopride $\mathrm{BP}_{\mathrm{ND}}$ following methylphenidate in hippocampus (percentage change $<0.60 \%$ ), but found robust changes in striatum $(7-10 \%)$. For completeness, we report $\mathrm{BP}_{\mathrm{ND}}$ values and statistics for all bilateral ROIs, as well as right and left hemispheres separately (Table 1). Left amygdala showed decreases in $\left[{ }^{11} \mathrm{C}\right]$ raclopride $\mathrm{BP}_{\mathrm{ND}}$ following methylphenidate (paired $t_{(29)}=2.84, p=0.01, d z=0.48$ ), which were absent in right amygdala (paired $t_{(29)}<1, d z=0.10$ ). As we did not have a priori hypotheses about laterality effects, functional connectivity and correlation analyses were conducted using bilateral ROIs. Hemisphere-specific analyses can be accessed at https://doi.org/10.6078/D1JM3K.

Although there is a precedent in the literature for interpreting $\left[{ }^{11} \mathrm{C}\right]$ raclopride $\mathrm{BP}_{\mathrm{ND}}$ outside of the striatum (Atzil et al., 2017; Lövdén et al., 2018) as well as interpreting dopamine release outside the striatum (Piccini et al., 2003; Sawamoto et al., 2008; Stokes et al., 2010; Volkow et al., 2014; Thanarajah et al., 2018), there are potential concerns that extra-striatal $\left[{ }^{11} \mathrm{C}\right]$ raclopride binding has a low signal-to-noise ratio to the extent that it precludes the valid measurement of $\mathrm{D} 2 / 3$ receptor binding and release in amygdala and rACC [but see Alakurtti et al., 2015 for demonstration of high test-retest reliability for $\left[{ }^{11} \mathrm{C}\right]$ raclopride in ACC (no reporting for amygdala)]. We therefore examined changes in binding in occipital cortex, which has low dopamine concentration (Brown et al., 1979; Camps et al., 1989) and would be expected to show minimal $\mathrm{BP}_{\mathrm{ND}}$ and dopamine release. Specifically, we sought to ensure that baseline $\mathrm{BP}_{\mathrm{ND}}$ and dopamine release measures in our extra-striatal ROIs surpassed measures observed for occipital cortex. Baseline $\left[{ }^{11} \mathrm{C}\right]$ raclopride $\mathrm{BP}_{\mathrm{ND}}$ (following placebo) was significantly lower in occipital cortex than in amygdala, rACC, and hippocampus (composite: $t_{(29)}=21.68$, $p<0.001, d z=4.05$; amygdala: $t_{(29)}=22.18, p<0.001, d z=$ 


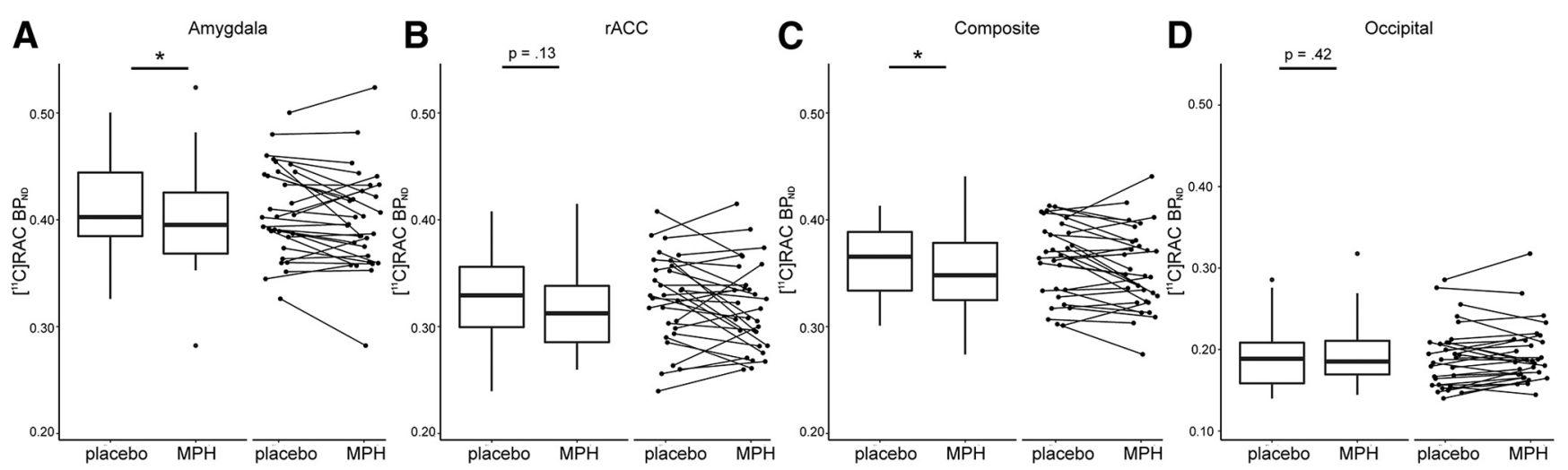

Figure 1. Dopamine release measured in amygdala, $\mathrm{rACC}$, and occipital cortex. Dopamine release measures were derived for each participant by comparing $\left[{ }^{11} \mathrm{C}\right]$ raclopride $\mathrm{BP}{ }_{\mathrm{ND}}$ following administration of placebo and following administration of methylphenidate (MPH). $\boldsymbol{A}-\boldsymbol{D}$, Box plots show variations in $\left[{ }^{11} \mathrm{C}\right]$ raclopride $\mathrm{BP}_{\mathrm{ND}}$ for placebo and methylphenidate conditions in $(\boldsymbol{A})$ amygdala, (B) rACC, ( () the composite ROl comprising both amygdala and rACC (weight averaged by volume), and (D) occipital cortex where dopamine release was expected to be minimal (note difference in scale). The line indicates the median, the box shows the interquartile range, and the whiskers are $1.5 \times$ the interquartile range. Data for individual participants is displayed in accompanying scatterplots. Asterisks indicate significant difference between placebo and MPH conditions $(p<.05)$.

Table 1. $\left[{ }^{11} \mathrm{C}\right]$ raclopride $\mathrm{BP}_{\mathrm{ND}}$ in ROls

\begin{tabular}{|c|c|c|c|c|c|c|}
\hline & \multicolumn{2}{|c|}{$\left.{ }^{11} \mathrm{C}\right]$ raclopride $\mathrm{BP}_{\mathrm{ND}}$} & \multicolumn{4}{|l|}{ Paired $t$ test } \\
\hline & Placebo & Methylphenidate & Change, $\%$ & $t$ & $p$ & $d z$ \\
\hline Composite ROI & $0.362 \pm 0.035$ & $0.354 \pm 0.038$ & 2.29 & 2.26 & 0.03 & 0.38 \\
\hline R amygdala & $0.400 \pm 0.044$ & $0.397 \pm 0.049$ & 0.67 & 0.59 & 0.56 & 0.10 \\
\hline L amygdala & $0.417 \pm 0.046$ & $0.403 \pm 0.047$ & 3.20 & 2.64 & 0.01 & 0.48 \\
\hline Bilateral rACC & $0.326 \pm 0.041$ & $0.318 \pm 0.041$ & 2.10 & 1.55 & 0.13 & 0.27 \\
\hline RrACC & $0.332 \pm 0.043$ & $0.324 \pm 0.045$ & 1.75 & 1.13 & 0.27 & 0.20 \\
\hline Roccipital & $0.195 \pm 0.039$ & $0.201 \pm 0.038$ & -0.04 & 1.67 & 0.11 & 0.31 \\
\hline L occipital & $0.188 \pm 0.042$ & $0.187 \pm 0.038$ & 0.00 & 0.33 & 0.75 & 0.06 \\
\hline Whole striatum & $3.347 \pm 0.228$ & $3.044 \pm 0.225$ & 8.98 & 10.65 & $<0.001$ & 2.63 \\
\hline Bilateral DCA & $3.039 \pm 0.248$ & $2.821 \pm 0.246$ & 7.13 & 9.22 & $<0.001$ & 1.70 \\
\hline R dorsal caudate & $3.029 \pm 0.243$ & $2.812 \pm 0.260$ & 7.16 & 8.51 & $<0.001$ & 1.58 \\
\hline L dorsal caudate & $3.050 \pm 0.262$ & $2.831 \pm 0.244$ & 7.05 & 7.70 & $<0.001$ & 1.42 \\
\hline R ventral striatum & $2.541 \pm 0.224$ & $2.335 \pm 0.221$ & 8.04 & 10.37 & $<0.001$ & 1.84 \\
\hline L ventral striatum & $2.667 \pm 0.257$ & $2.457 \pm 0.264$ & 7.83 & 8.89 & $<0.001$ & 1.63 \\
\hline Bilateral hippocampus & $0.308 \pm 0.030$ & $0.307 \pm 0.035$ & 0.52 & 0.46 & 0.65 & 0.08 \\
\hline Rhippocampus & $0.302 \pm 0.028$ & $0.303 \pm 0.035$ & -0.39 & 0.19 & 0.85 & 0.03 \\
\hline L hippocampus & $0.314 \pm 0.037$ & $0.310 \pm 0.039$ & 0.97 & 0.77 & 0.45 & 0.14 \\
\hline
\end{tabular}
manually segmented. R, Right; L, left.

2.98; rACC: $t_{(29)}=16.35, p<0.001, d z=3.82$; hippocampus: $\left.t_{(29)}=16.51, p<0.001, d z=3.01\right)$. In occipital cortex, there was no significant change in $\left[{ }^{11} \mathrm{C}\right]$ raclopride $\mathrm{BP}_{\mathrm{ND}}$ following methylphenidate administration (paired $t_{(29)}<1, p=0.42, d z=0.15$; percentage change in $\left.\mathrm{BP}_{\mathrm{ND}}=-1.99 \pm 8.71\right)$. Dopamine release (percentage change in $\mathrm{BP}_{\mathrm{ND}}$ ) measured in bilateral amygdala and rACC was significantly greater than dopamine release measured in occipital cortex (composite: $t_{(29)}=2.64, p=0.01, d z=0.48$; amygdala: $t_{(29)}=2.26, p=0.03, d z=0.41$; rACC: $t_{(29)}=2.17$, $p=0.04, d z=0.40)$. However, dopamine release was not significantly greater in hippocampus than in occipital cortex $\left(t_{(29)}=\right.$ 1.53, $p=0.14, d z=0.28)$. These results support the use of $\left[{ }^{11} \mathrm{C}\right]$ raclopride-derived measures of dopamine release in rACC and amygdala ROIs. Given concerns about low signal-to-noise in regions with low $\mathrm{D} 2 / 3$ receptor density, we do not believe the $\left[{ }^{11} \mathrm{C}\right]$ raclopride-derived hippocampal dopamine release mea- sure should be interpreted. Baseline $\left[{ }^{11} \mathrm{C}\right]$ raclopride $\mathrm{BP}_{\mathrm{ND}}$ was significantly lower in hippocampus than amygdala $\left(t_{(29)}=16.55\right.$, $p<0.001, d z=3.00)$ and $\operatorname{rACC}\left(t_{(29)}=2.58, p=0.02\right.$, $d z=0.48)$. We therefore do not report correlations with $\left[{ }^{11} \mathrm{C}\right]$ raclopride-derived dopamine release measures in hippocampus here.

\section{Functional connectivity}

Resting-state functional connectivity was acquired following placebo administration. Participants were blind to the treatment condition, and, as a group, were not able to accurately guess the treatment condition at the end of the experimental session $(50 \%$ accuracy). Resting-state analyses measured ROI-to-ROI functional connectivity between amygdala and rACC [mean $z$-transformed Pearson correlation ( $\mathrm{M} \pm \mathrm{SD}$ ): $0.28 \pm 0.21]$. There was not a significant difference in rACC-amygdala functional con- 


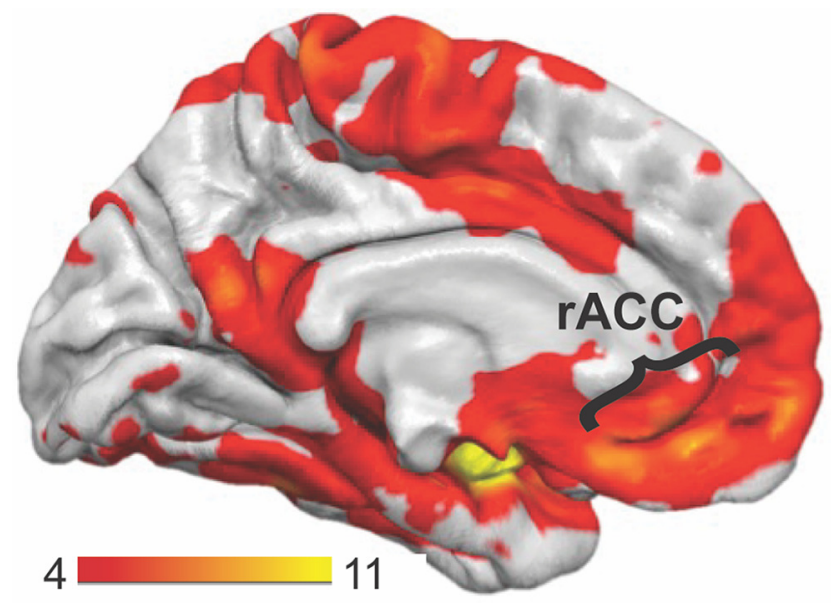

Figure 2. Resting functional connectivity. The voxelwise resting-state functional connectivity map is displayed with bilateral amygdala used as the seed region. The scale bar indicates $t$ values. Significance thresholding revealed a single cluster that was comprised of prefrontal cortex (including rACC and medial frontal gyrus), limbic regions (including parahippocampal gyrus, hippocampus, and insula), and posterior regions (including motor, premotor, and posterior cingulate cortices).

nectivity for those who believed they were in the placebo condition versus those who believed they were in the drug condition (independent $t$ test: $t_{(28)}<1$ ). Across the experimental session, self-reported anxiety measured with visual analog scale did not correlate with rACC-amygdala functional connectivity ( $r$ range -0.07 to 0.19 ), and did not differ between those who thought they were in a drug versus placebo condition (independent $t$ test: $\left.t_{(28)}<1\right)$. Control analyses measured resting-state functional connectivity between amygdala and occipital cortex (0.04 \pm 0.03 ). Exploratory voxelwise analysis confirmed that, on a group level, amygdala showed significant functional connectivity with a single cluster comprising frontal regions including rACC and ventral medial PFC, limbic and temporal lobe regions including insula and hippocampus, motor regions, and posterior cingulate/ precuneus (Fig. 2). The unthresholded voxelwise map is publicly available at https://neurovault.org/collections/4666/.

\section{Associations between trait anxiety and dopamine release}

Primary analyses examined relationships between trait anxiety and dopamine release in the composite rACC-amygdala ROI. Trait anxiety was negatively associated with dopamine release [composite ROI: $r=-0.44(-0.69,-0.15)$; Fig. $3 A$ ]. Anxiety was not associated with dopamine release in occipital cortex $[r=$ $-0.04(-0.40,0.33)]$. These correlations were statistically different from one another for a one-tailed significance test $(z=1.89$, $p=0.03)$ and were marginal for a two-tailed test $(p=0.06)$. Exploratory post hoc analyses examined whether dopamine release in either amygdala or rACC was independently related to trait anxiety, and revealed significant relationships in both amygdala $[r=-0.31(-0.55,-0.05)]$ and $\operatorname{rACC}[r=-0.35$ $(-0.64,-0.04)]$ with no difference in the strength of these correlations $(z=0.18, p=0.86)$. To probe whether dopamineanxiety relationships were specific to dopamine release, we tested whether placebo [ ${ }^{11} \mathrm{C}$ ] raclopride $\mathrm{BP}_{\mathrm{ND}}$ was correlated with anxiety, and found no relationship [composite ROI: $r=-0.08$ $(-0.43,0.27)]$.

Because of potential interest in correlations between anxiety and dopamine release in striatal subregions, we report those correlations here. Trait anxiety was not correlated with dopamine release in the whole striatum $[r=-0.22(-56,0.16)]$, DPUT $[r=-0.16(-0.52,0.34)]$, or VST $[r=-0.14(-0.53,0.27)]$, but was correlated with dopamine release in DCA $[r=-0.40(-0.64$, $-0.08)$ ]. The direction of this relationship is consistent with those found for amygdala and rACC such that lower dopamine release was associated with higher trait anxiety.

\section{Associations between trait anxiety and functional connectivity}

Trait anxiety was significantly related to rACC-amygdala functional connectivity [a priori ROI-to-ROI analysis, $r=0.32(0.03$, 0.56); Fig. $3 B$ ]. We found no relationship between trait anxiety and occipital-amygdala functional connectivity $[r=0.27$ $(-0.11,0.59)]$. These correlations were not statistically different from one another $(z=0.29$, two-tailed $p=0.77)$. Exploratory voxelwise regression using trait anxiety as a predictor showed no clusters that exceeded the $3 \mathrm{dCl}$ (ustSim significance threshold.

\section{Associations between dopamine release and functional connectivity}

Lower rACC-amygdala functional connectivity measured in the a priori ROI-to-ROI analysis was associated with higher dopamine release [composite ROI: $r=-0.52(-0.76,-0.17)$; Fig. $3 C]$. However, these results should be interpreted with caution as the skipped Pearson robust regression method identified three outlying data points in this analysis, which are shown in Figure $3 C$ (gray). Exploratory post hoc analyses examined whether dopamine release in either amygdala or rACC was independently related to rACC-amygdala functional connectivity. These analyses demonstrated that the negative relationship was not driven by dopamine release in either region individually, as correlations were not significantly different $(z=0.44, p=0.66)$, though did not reach significance individually [amygdala; $r=-0.22(-0.59$, $0.26)$; rACC; $r=-0.32(-0.65,0.05)]$. For control analyses, occipital-amygdala functional connectivity was not associated with dopamine release in occipital cortex $(r=-0.16,(-0.50,0.18)]$ or dopamine release in a composite amygdala/occipital ROI $[r=$ $-0.17(-0.49,0.20)]$.

Correlations for occipital-amygdala and rACC-amygdala analyses were statistically different from one another for a onetailed significance test $(z=1.72, p=0.04)$ and were marginal for a two-tailed test $(p=0.08)$. To probe whether relationships were specific to dopamine release, we tested whether placebo $\left[{ }^{11} \mathrm{C}\right] \mathrm{ra}-$ clopride $\mathrm{BP}_{\mathrm{ND}}$ was correlated with rACC-amygdala functional connectivity, and found no relationship [composite ROI: $r=$ $-0.05(-0.43,0.27)]$. Exploratory voxelwise regression analysis using amygdala dopamine release as a predictor showed no clusters that exceeded the $3 \mathrm{dClustSim}$ significance threshold.

\section{Discussion}

We demonstrate that normal variation in trait anxiety is associated with individual differences in dopamine release in amygdala and rACC in humans. These findings support the view that variation in trait anxiety in nonclinical populations may arise, at least in part, from individual differences in neurochemistry and activity within a corticolimbic rACC-amygdala network. Additionally, we found preliminary evidence for relationships between dopamine release and rACC-amygdala functional connectivity. These results highlight the potential value of integrating PET measures of neurotransmitter release with fMRI to understand individual differences in functional connectivity in humans.

We found that higher trait anxiety was associated with higher baseline rACC-amygdala functional connectivity measured with 
A

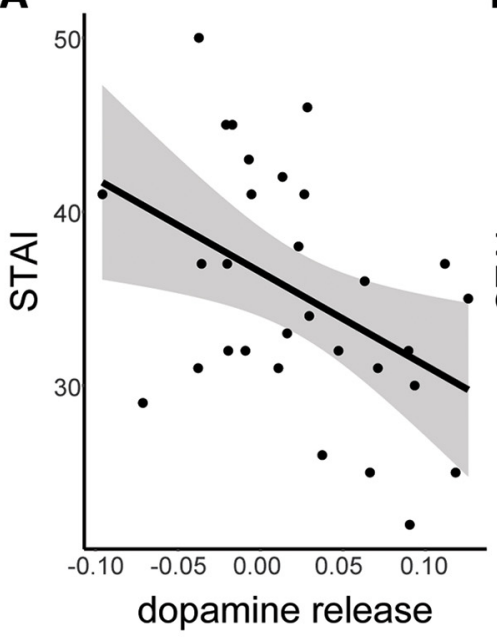

B

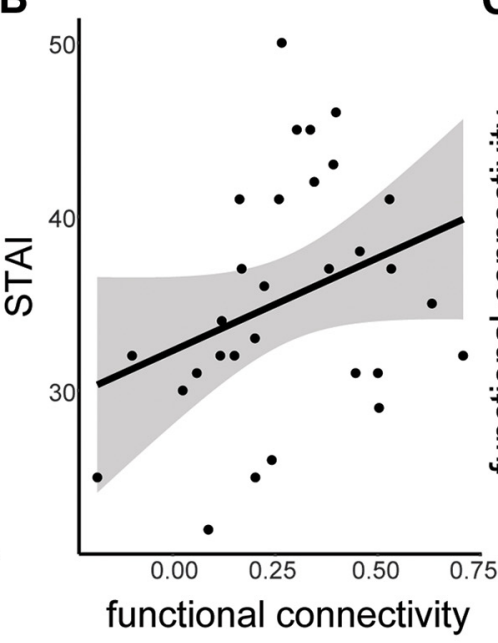

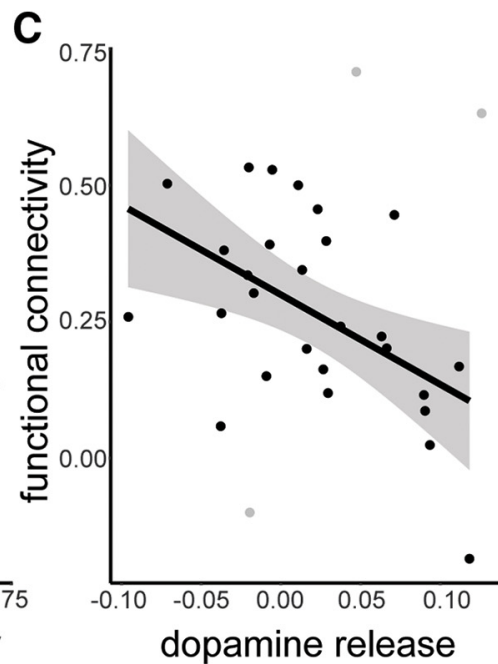
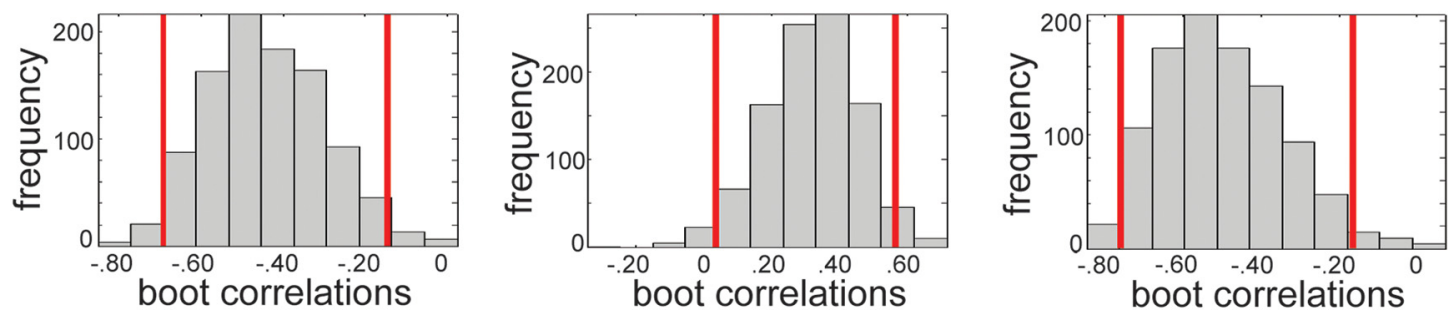

Figure 3. Interrelationships between dopamine release, trait anxiety, and functional connectivity. $\boldsymbol{A}$, Dopamine release and trait anxiety showed a negative relationship $[r=-0.44$, $\mathrm{Cl}=$ $(-0.69,-0.15)$ ] such that people with greater dopamine release in the composite ROI (amygdala and rACC) had lower trait anxiety. The histogram of correlation values for bootstrapped data is provided below. $\boldsymbol{B}$, Functional connectivity measured between bilateral amygdala and $\mathrm{rACC}$ showed a positive relationship with trait anxiety $[r=0.32, \mathrm{Cl}=(0.03,0.56)]$. $\boldsymbol{C}$, Functional $\operatorname{connectivity}$ and dopamine release were negatively related $[r=-0.52, \mathrm{Cl}=(-0.76,-0.17)]$ such that people with stronger connectivity showed lower dopamine release. Those subjects identified as outlying data points in the skipped Pearson robust regression method are shown in gray.

resting-state fMRI. The direction of this relationship is consistent with some previous studies (Baeken et al., 2014; Qin et al., 2014; He et al., 2016), though others have reported negative relationships (Coombs et al., 2014), and stronger negative correlations between amygdala and rACC in higher anxiety individuals (Kim et al., 2011). Future work is needed to understand the factors underlying variability in the direction of findings, which may include fMRI study design. In fMRI studies in which participants are exposed to unpleasant or threatening stimuli, successful engagement of rACC has been interpreted to reflect regulatory control mechanisms to suppress amygdala hyperactivity (Bishop, 2007). People with anxiety disorders often show diminished rACCamygdala correlated activity (Prater et al., 2013; Stevens et al., 2013; Brown et al., 2014), and dampened activation in PFC when attempting to engage emotional regulation strategies such as cognitive reappraisal (for review, see Zilverstand et al., 2017). In the present study, participants took an oral placebo before the fMRI, but were blind to the treatment condition. It is possible that participants with higher trait anxiety experienced greater unease because of drug expectancy. In the healthy population studied here, correlated rACC-amygdala activity in higher trait anxiety subjects may simply reflect functional engagement of the system when under mild duress. It is worth noting that such an explanation is purely speculative, particularly given that we found no evidence that self-reported "state" anxiety at any point during the experimental session (visual analog scale) was related to rACCamygdala functional connectivity.

The positive relationship between dopamine release and trait anxiety lends support for hypodopaminergic accounts of anxiety (Taylor et al., 1982; Walsh and Bennett, 2001). The direction of this relationship is consistent with observations in Parkinson's disease in which the prevalence of comorbid anxiety is estimated to be as high as $40 \%$ (Richard et al., 1996), and often precedes the onset of motor symptoms (Chaudhuri et al., 2006). Whereas levodopa treatment has been successful in reducing anxiety symptoms in patients (Maricle et al., 1995), dopaminergic agonists and amphetamines can have anxiogenic effects in people without severe dopaminergic depletion (Berman et al., 2009). These effects are consistent with a Yerkes-Dodson relationship such that augmentation of dopamine acts to reduce anxiety until a tipping point after which higher levels elevate anxiety. Such "overdose" effects of dopamine on cognition and brain activity have been observed in animal models and humans (Vijayraghavan et al., 2007; Dreher et al., 2008; Cools et al., 2009; Gjedde et al., 2010; Berry et al., 2016). It is possible, however, that subtle manipulations have therapeutic effects. The drug buspirone acts as both a partial agonist for 5HT1A receptors and a weak antagonist for D2 autoreceptors, increasing dopamine release (Gobert et al., 1999). The anxiolytic action of buspirone (Goldberg and Finnerty, 1979) has largely been attributed to its serotonergic action, with little systematic investigation of dopamine's independent or conjoint effects on anxiety.

Investigation of altered dopamine function in affective disorders have largely focused on dopamine PET markers in striatum. Together these studies offer mixed results (for review, see Savitz and Drevets, 2013; Cervenka, 2019). Studies of patients with social anxiety disorders have demonstrated dopamine transporter densities in whole striatum that are lower (Tiihonen et al., 1997), higher (van der Wee et al., 2008), and not different (Schneier et al., 2009) from controls. Similarly, there have been reports sug- 
gesting reduced D2/3 receptor availability (whole striatum) in patients with social anxiety (Schneier et al., 2000) and comorbid obsessive-compulsive disorder (Schneier et al., 2008), though these effects have not replicated in a larger sample (Schneier et al., 2009). Deep-brain stimulation of the dopamine-rich nucleus accumbens can reduce anxiety symptoms in patients with anxiety and obsessive-compulsive disorders (Sturm et al., 2003; Denys et al., 2010), providing indirect evidence for dopaminergic mechanisms of anxiety. Though examining relationships between striatal dopamine release and anxiety was not a central aim, our data suggested higher trait anxiety was associated with lower dopamine release in DCA. These findings should be interpreted with caution as they were not consistent for other striatal subregions, particularly for VST, which includes nucleus accumbens and whose association with limbic processes has been most clearly established (Sharp, 2017). These findings in DCA may, however, be a launching point for future hypothesis testing.

Our findings receive general support from studies associating dopamine with corticolimbic responses to emotionally salient stimuli in healthy populations (Hariri et al., 2002; Tessitore et al., 2002; Takahashi et al., 2005; Kienast et al., 2008b; Blasi et al., 2009; Lonsdorf et al., 2011; Atzil et al., 2017). For example, PET measurement of dopamine storage capacity $\left(\mathrm{V}_{\mathrm{d}}\right)$ revealed a correlation between amygdala $\mathrm{V}_{\mathrm{d}}$ and activation in both amygdala and ACC (Kienast et al., 2008a). Similarly, individuals with a genetic polymorphism that may increase dopamine transporter expression (SLC6A3, 3' untranslated region 9-repeat), show elevated amygdala reactivity (Bergman et al., 2014). These findings may be consistent with hypodopaminergic accounts of anxiety, given known positive relationships between amygdala reactivity and anxiety (Bishop et al., 2004; Etkin et al., 2004). However, relationships between storage capacity or genetically inferred differences in transporter density and extracellular dopamine concentration have not been established.

This study is unique in the connection it revealed between two functional brain measurements taken during task-absent baseline conditions: fMRI functional connectivity and a PET neurochemical measure reflecting dopamine release (for recent studies examining relationships between fMRI functional connectivity and static dopamine PET measures, see Nyberg et al., 2016; Berry et al., 2018c; Rieckmann et al., 2018). Evidence of a negative relationship between functional connectivity and dopamine release in humans is potentially of general interest. Although precise circuit structure is beyond the scope of the present study, there are candidate mechanisms established in animal models by which local increases in dopamine release may suppress activity within corticolimbic circuits. For example, stimulation of ventral tegmental area inputs to the amygdala inhibits activity of efferent amygdala projections while attenuating the activity of medial PFC inputs to the amygdala (Rosenkranz and Grace, 1999). This offers a possible mechanism by which local increases in dopamine release may suppress amygdala functional connectivity generally and rACC-amygdala functional connectivity specifically.

The present study has a number of limitations. First, fMRI and PET data were acquired during separate sessions, which may have interfered with the detection of consistent relationships between dopamine release and rACC-amygdala functional connectivity especially given the time delay between sessions. Future studies using simultaneous fMRI and PET acquisition are warranted and could extend our findings by using longer resting-state scans in which dynamic changes in correlated fMRI activity, and potentially receptor binding may be possible. This study is also limited by the use of self-report measures for trait anxiety. Investigating dynamics of functional connectivity changes or dopamine release during social stress paradigms with experiential sampling would shed light on the nature of recruitment of these circuits in an ecologically relevant way. Further, it will be critical to demonstrate that our findings can be replicated using higher affinity radiotracers, though methylphenidate-derived release measures are not as established with tracers such as fallypride. Such studies could be especially useful for probing discrete contributions of hippocampal dopamine in specific aspects of anxiety. Although methylphenidate-paired $\left[{ }^{11} \mathrm{C}\right]$ raclopride PET was sufficient for detecting change in $\mathrm{BP}_{\mathrm{ND}}$ in amygdala and rACC ROIs significantly exceeding occipital cortex, this was not the case for hippocampus. Fruitful studies using fallypride could probe relationships between individual differences in hippocampal dopamine, trait anxiety, and passive avoidance behavior (Gray and McNaughton, 2000; Bach et al., 2014; O’Neil et al., 2015; Loh et al., 2017).

Together, these multimodal findings offer insights into relationships between correlated fMRI activity and neurochemical signaling relevant to individual differences in affective function in humans. Beyond contributions to our understanding of the dopaminergic mechanisms underlying variability in trait anxiety, this study provides a proof of concept that measures of endogenous neuromodulator release may be paired with intrinsic fMRI connectivity to inform essential questions in human cognitive and affective neuroscience. Notably, relationships between dopamine function and resting-state fMRI activity were not revealed using the standard baseline $\mathrm{D} 2 / 3 \mathrm{BP}_{\mathrm{ND}}\left[{ }^{11} \mathrm{C}\right]$ raclopride measure, suggesting measurement of dopamine release is a particularly useful tool for investigating functional circuit activity. Such efforts can shed light on the fundamental nature of interactions between neurochemistry and neural network activity while offering exciting promise for advancing translational research that bridges findings in humans and animal models.

\section{References}

Alakurtti K, Johansson JJ, Joutsa J, Laine M, Bäckman L, Nyberg L, Rinne JO (2015) Long-term test-retest reliability of striatal and extrastriatal dopamine $\mathrm{D} 2 / 3$ receptor binding: study with $\left[{ }^{11} \mathrm{C}\right]$ raclopride and highresolution PET. J Cereb Blood Flow Metab 35:1199-1205.

Angrist BM, Gershon S (1970) The phenomenology of experimentally induced amphetamine psychosis: preliminary observations. Biol Psychiatry 2:95-107.

Atzil S, Touroutoglou A, Rudy T, Salcedo S, Feldman R, Hooker JM, Dickerson BC, Catana C, Barrett LF (2017) Dopamine in the medial amygdala network mediates human bonding. Proc Natl Acad Sci U S A 114:23612366.

Bach DR, Guitart-Masip M, Packard PA, Miró J, Falip M, Fuentemilla L, Dolan RJ (2014) Human hippocampus arbitrates approach-avoidance conflict. Curr Biol CB 24:541-547.

Baeken C, Marinazzo D, Van Schuerbeek P, Wu GR, De Mey J, Luypaert R, De Raedt R (2014) Left and right amygdala- mediofrontal cortical functional connectivity is differentially modulated by harm avoidance. PloS One 9:e95740.

Bergman O, Åhs F, Furmark T, Appel L, Linnman C, Faria V, Bani M, Pich EM, Bettica P, Henningsson S, Manuck SB, Ferrell RE, Nikolova YS, Hariri AR, Fredrikson M, Westberg L, Eriksson E (2014) Association between amygdala reactivity and a dopamine transporter gene polymorphism. Transl Psychiatry 4:e420.

Berman SM, Kuczenski R, McCracken JT, London ED (2009) Potential adverse effects of amphetamine treatment on brain and behavior: a review. Mol Psychiatry 14:123-142.

Berry AS, Shah VD, Baker SL, Vogel JW, O’Neil JP, Janabi M, Schwimmer HD, Marks SM, Jagust WJ (2016) Aging affects dopaminergic neural mechanisms of cognitive flexibility. J Neurosci 36:12559-12569.

Berry AS, Jagust WJ, Hsu M (2018a) Age-related variability in decisionmaking: insights from neurochemistry. Cogn Affect Behav Neurosci. 
Advance online publication. Retrieved February 13, 2019. doi: 10.3758/s13415-018-00678-9.

Berry AS, Shah VD, Furman DJ, White RL 3rd, Baker SL, O'Neil JP, Janabi M, D’Esposito M, Jagust WJ (2018b) Dopamine synthesis capacity is associated with D2/3 receptor binding but not dopamine release. Neuropsychopharmacology 43:1201-1211.

Berry AS, Shah VD, Jagust WJ (2018c) The influence of dopamine on cognitive flexibility is mediated by functional connectivity in young but not older adults. J Cogn Neurosci 30:1330-1344.

Bishop SJ (2007) Neurocognitive mechanisms of anxiety: an integrative account. Trends Cogn Sci 11:307-316.

Bishop SJ, Duncan J, Lawrence AD (2004) State anxiety modulation of the amygdala response to unattended threat-related stimuli. J Neurosci 24:10364-10368.

Bissière S, Plachta N, Hoyer D, McAllister KH, Olpe HR, Grace AA, Cryan JF (2008) The rostral anterior cingulate cortex modulates the efficiency of amygdala-dependent fear learning. Biol Psychiatry 63:821-831.

Blasi G, Lo Bianco L, Taurisano P, Gelao B, Romano R, Fazio L, Papazacharias A, Di Giorgio A, Caforio G, Rampino A, Masellis R, Papp A, Ursini G, Sinibaldi L, Popolizio T, Sadee W, Bertolino A (2009) Functional variation of the dopamine D2 receptor gene is associated with emotional control as well as brain activity and connectivity during emotion processing in humans. J Neurosci 29:14812-14819.

Breier A, Su TP, Saunders R, Carson RE, Kolachana BS, de Bartolomeis A, Weinberger DR, Weisenfeld N, Malhotra AK, Eckelman WC, Pickar D (1997) Schizophrenia is associated with elevated amphetamine-induced synaptic dopamine concentrations: evidence from a novel positron emission tomography method. Proc Natl Acad Sci U S A 94:2569-2574.

Brown RM, Crane AM, Goldman PS (1979) Regional distribution of monoamines in the cerebral cortex and subcortical structures of the rhesus monkey: concentrations and in vivo synthesis rates. Brain Res 168:133150.

Brown VM, LaBar KS, Haswell CC, Gold AL, Mid-Atlantic MIRECC Workgroup, McCarthy G, Morey RA (2014) Altered resting-state functional connectivity of basolateral and centromedial amygdala complexes in posttraumatic stress disorder. Neuropsychopharmacology 39:351-359.

Camps M, Cortés R, Gueye B, Probst A, Palacios JM (1989) Dopamine receptors in human brain: autoradiographic distribution of D2 sites. Neuroscience 28:275-290.

Cervenka S (2019) PET radioligands for the dopamine D1-receptor: application in psychiatric disorders. Neurosci Lett 691:26-34.

Chaudhuri KR, Healy DG, Schapira AH, National Institute for Clinical Excellence (2006) Non-motor symptoms of Parkinson's disease: diagnosis and management. Lancet Neurol 5:235-245.

Cools R, Frank MJ, Gibbs SE, Miyakawa A, Jagust W, D’Esposito M (2009) Striatal dopamine predicts outcome-specific reversal learning and its sensitivity to dopaminergic drug administration. J Neurosci 29:1538-1543.

Coombs G 3rd, Loggia ML, Greve DN, Holt DJ (2014) Amygdala perfusion is predicted by its functional connectivity with the ventromedial prefrontal cortex and negative affect. PloS One 9:e97466.

Dang LC, Castrellon JJ, Perkins SF, Le NT, Cowan RL, Zald DH, SamanezLarkin GR (2017) Reduced effects of age on dopamine D2 receptor levels in physically active adults. Neuroimage 148:123-129.

David V, Gold LH, Koob GF, Cazala P (2001) Anxiogenic-like effects limit rewarding effects of cocaine in BALB/CBYJ mice. Neuropsychopharmacology 24:300-318.

Davidson RJ (2002) Anxiety and affective style: role of prefrontal cortex and amygdala. Biol Psychiatry 51:68-80.

Dedic N, Kühne C, Jakovcevski M, Hartmann J, Genewsky AJ, Gomes KS, Anderzhanova E, Pöhlmann ML, Chang S, Kolarz A, Vogl AM, Dine J, Metzger MW, Schmid B, Almada RC, Ressler KJ, Wotjak CT, Grinevich V, Chen A, Schmidt MV, et al. (2018) Chronic CRH depletion from GABAergic, long-range projection neurons in the extended amygdala reduces dopamine release and increases anxiety. Nat Neurosci 21:803-807.

Denys D, Mantione M, Figee M, van den Munckhof P, Koerselman F, Westenberg H, Bosch A, Schuurman R (2010) Deep brain stimulation of the nucleus accumbens for treatment-refractory obsessive-compulsive disorder. Arch Gen Psychiatry 67:1061-1068.

Dreher JC, Meyer-Lindenberg A, Kohn P, Berman KF (2008) Age-related changes in midbrain dopaminergic regulation of the human reward system. Proc Natl Acad Sci U S A 105:15106-15111.

Endres CJ, Kolachana BS, Saunders RC, Su T, Weinberger D, Breier A, Eck- elman WC, Carson RE (1997) Kinetic modeling of $\left[{ }^{11} \mathrm{C}\right]$ raclopride: combined PET-microdialysis studies. J Cereb Blood Flow Metab 17:932-942.

Etkin A, Klemenhagen KC, Dudman JT, Rogan MT, Hen R, Kandel ER, Hirsch J (2004) Individual differences in trait anxiety predict the response of the basolateral amygdala to unconsciously processed fearful faces. Neuron 44:1043-1055.

Etkin A, Egner T, Peraza DM, Kandel ER, Hirsch J (2006) Resolving emotional conflict: a role for the rostral anterior cingulate cortex in modulating activity in the amygdala. Neuron 51:871-882.

Fonzo GA, Etkin A (2017) Affective neuroimaging in generalized anxiety disorder: an integrated review. Dialogues Clin Neurosci 19:169-179.

Friston K, Ashburner J, Kiebel S, Nichols T, Penny W eds (2007) Front matter. In: Statistical parametric mapping, pp iii. London: Academic.

Gjedde A, Kumakura Y, Cumming P, Linnet J, Møller A (2010) Inverted-Ushaped correlation between dopamine receptor availability in striatum and sensation seeking. Proc Natl Acad Sci U S A 107:3870-3875.

Gobert AP, Vincendeau P, Mossalayi D, Veyret B (1999) Mechanism of extracellular thiol nitrosylation by $\mathrm{N}_{2} \mathrm{O}_{3}$ produced by activated macrophages. Nitric Oxide 3:467-472.

Goldberg HL, Finnerty RJ (1979) The comparative efficacy of buspirone and diazepam in the treatment of anxiety. Am J Psychiatry 136:11841187.

Gray JA, McNaughton N (2000) The neuropsychology of anxiety: an enquiry into the functions of the septo-hippocampal system. New York: Oxford UP.

Gunn RN, Lammertsma AA, Hume SP, Cunningham VJ (1997) Parametric imaging of ligand-receptor binding in PET using a simplified reference region model. Neuroimage 6:279-287.

Hall H, Sedvall G, Magnusson O, Kopp J, Halldin C, Farde L (1994) Distribution of D1- and D2-dopamine receptors, and dopamine and its metabolites in the human brain. Neuropsychopharmacology 11:245-256.

Hariri AR, Mattay VS, Tessitore A, Fera F, Smith WG, Weinberger DR (2002) Dextroamphetamine modulates the response of the human amygdala. Neuropsychopharmacology 27:1036-1040.

He Y, Xu T, Zhang W, Zuo XN (2016) Lifespan anxiety is reflected in human amygdala cortical connectivity. Hum Brain Mapp 37:1178-1193.

Javoy-Agid F, Agid Y (1980) Is the mesocortical dopaminergic system involved in Parkinson disease? Neurology 30:1326-1330.

Jonasson LS, Axelsson J, Riklund K, Braver TS, Ögren M, Bäckman L, Nyberg L (2014) Dopamine release in nucleus accumbens during rewarded task switching measured by $\left[{ }^{11} \mathrm{C}\right]$ raclopride. Neuroimage 99:357-364.

Kessler RM, Whetsell WO, Ansari MS, Votaw JR, de Paulis T, Clanton JA, Schmidt DE, Mason NS, Manning RG (1993) Identification of extrastriatal dopamine D2 receptors in postmortem human brain with $\left[{ }^{125} \mathrm{I}\right]$ epidepride. Brain Res 609:237-243.

Kienast T, Hariri AR, Schlagenhauf F, Wrase J, Sterzer P, Buchholz HG, Smolka MN, Gründer G, Cumming P, Kumakura Y, Bartenstein P, Dolan RJ, Heinz A (2008a) Dopamine in amygdala gates limbic processing of aversive stimuli in humans. Nat Neurosci 11:1381-1382.

Kienast T, Siessmeier T, Wrase J, Braus DF, Smolka MN, Buchholz HG, Rapp M, Schreckenberger M, Rösch F, Cumming P, Gruender G, Mann K, Bartenstein P, Heinz A (2008b) Ratio of dopamine synthesis capacity to D2 receptor availability in ventral striatum correlates with central processing of affective stimuli. Eur J Nucl Med Mol Imaging 35:1147-1158.

Kim MJ, Gee DG, Loucks RA, Davis FC, Whalen PJ (2011) Anxiety dissociates dorsal and ventral medial prefrontal cortex functional connectivity with the amygdala at rest. Cereb Cortex 21:1667-1673.

Kuczenski R, Segal DS (1997) Effects of methylphenidate on extracellular dopamine, serotonin, and norepinephrine: comparison with amphetamine. J Neurochem 68:2032-2037.

Loh E, Kurth-Nelson Z, Berron D, Dayan P, Duzel E, Dolan R, Guitart-Masip M (2017) Parsing the role of the hippocampus in approach-avoidance conflict. Cereb Cortex 27:201-215.

Lonsdorf TB, Golkar A, Lindstöm KM, Fransson P, Schalling M, Ohman A, Ingvar M (2011) 5-HTTLPR and COMTval158met genotype gate amygdala reactivity and habituation. Biol Psychol 87:106-112.

Lövdén M, Karalija N, Andersson M, Wåhlin A, Axelsson J, Köhncke Y, Jonasson LS, Rieckman A, Papenberg G, Garrett DD, Guitart-Masip M, Salami A, Riklund K, Bäckman L, Nyberg L, Lindenberger U (2018) Latent-profile analysis reveals behavioral and brain correlates of dopaminecognition associations. Cereb Cortex 28:3894-3907. 
Maricle RA, Nutt JG, Valentine RJ, Carter JH (1995) Dose-response relationship of levodopa with mood and anxiety in fluctuating Parkinson's disease: a double-blind, placebo-controlled study. Neurology 45:1757-1760.

Mawlawi O, Martinez D, Slifstein M, Broft A, Chatterjee R, Hwang DR, Huang Y, Simpson N, Ngo K, Van Heertum R, Laruelle M (2001) Imaging human mesolimbic dopamine transmission with positron emission tomography: I. Accuracy and precision of $\mathrm{D}_{2}$ receptor parameter measurements in ventral striatum. J Cereb Blood Flow Metab 21:1034-1057.

Moeller SJ, Konova AB, Parvaz MA, Tomasi D, Lane RD, Fort C, Goldstein RZ (2014) Functional, structural, and emotional correlates of impaired insight in cocaine addiction. JAMA Psychiatry 71:61-70.

Monchi O, Ko JH, Strafella AP (2006) Striatal dopamine release during performance of executive functions: a $\left[{ }^{11} \mathrm{C}\right]$ raclopride PET study. Neuroimage 33:907-912.

Nyberg L, Karalija N, Salami A, Andersson M, Wåhlin A, Kaboovand N, Köhncke Y, Axelsson J, Rieckmann A, Papenberg G, Garrett DD, Riklund K, Lövdén M, Lindenberger U, Bäckman L (2016) Dopamine D2 receptor availability is linked to hippocampal-caudate functional connectivity and episodic memory. Proc Natl Acad Sci U S A 113:7918-7923.

O’Neil EB, Newsome RN, Li IH, Thavabalasingam S, Ito R, Lee AC (2015) Examining the role of the human hippocampus in approach-avoidance decision making using a novel conflict paradigm and multivariate functional magnetic resonance imaging. J Neurosci 35:15039-15049.

Ouchi Y, Yoshikawa E, Okada H, Futatsubashi M, Sekine Y, Iyo M, Sakamoto M (1999) Alterations in binding site density of dopamine transporter in the striatum, orbitofrontal cortex, and amygdala in early Parkinson's disease: compartment analysis for $\beta$-CFT binding with positron emission tomography. Ann Neurol 45:601-610.

Pernet CR, Wilcox R, Rousselet GA (2012) Robust correlation analyses: false positive and power validation using a new open source MATLAB toolbox. Front Psychol 3:606.

Piccini P, Pavese N, Brooks DJ (2003) Endogenous dopamine release after pharmacological challenges in Parkinson's disease. Ann Neurol 53: 647-653.

Prater KE, Hosanagar A, Klumpp H, Angstadt M, Phan KL (2013) Aberrant amygdala-frontal cortex connectivity during perception of fearful faces and at rest in generalized social anxiety disorder. Depress Anxiety 30:234-241.

Qin S, Young CB, Duan X, Chen T, Supekar K, Menon V (2014) Amygdala subregional structure and intrinsic functional connectivity predicts individual differences in anxiety during early childhood. Biol Psychiatry 75:892-900.

Refojo D, Schweizer M, Kuehne C, Ehrenberg S, Thoeringer C, Vogl AM, Dedic N, Schumacher M, von Wolff G, Avrabos C, Touma C, Engblom D, Schütz G, Nave KA, Eder M, Wotjak CT, Sillaber I, Holsboer F, Wurst W, Deussing JM (2011) Glutamatergic and dopaminergic neurons mediate anxiogenic and anxiolytic effects of CRHR1. Science 333:1903-1907.

Richard IH, Schiffer RB, Kurlan R (1996) Anxiety and Parkinson's disease. J Neuropsychiatry Clin Neurosci 8:383-392.

Rieckmann A, Johnson KA, Sperling RA, Buckner RL, Hedden T (2018) Dedifferentiation of caudate functional connectivity and striatal dopamine transporter density predict memory change in normal aging. Proc Natl Acad Sci U S A 115:10160-10165.

Rosenkranz JA, Grace AA (1999) Modulation of basolateral amygdala neuronal firing and afferent drive by dopamine receptor activation in vivo. J Neurosci 19:11027-11039.

Rosenkranz JA, Grace AA (2002) Cellular mechanisms of infralimbic and prelimbic prefrontal cortical inhibition and dopaminergic modulation of basolateral amygdala neurons in vivo. J Neurosci 22:324-337.

Savitz JB, Drevets WC (2013) Neuroreceptor imaging in depression. Neurobiol Dis 52:49-65.

Sawamoto N, Piccini P, Hotton G, Pavese N, Thielemans K, Brooks DJ (2008) Cognitive deficits and striato-frontal dopamine release in Parkinson's disease. Brain 131:1294-1302.

Schneier FR, Liebowitz MR, Abi-Dargham A, Zea-Ponce Y, Lin SH, Laruelle M (2000) Low dopamine $\mathrm{D}_{2}$ receptor binding potential in social phobia. Am J Psychiatry 157:457-459.

Schneier FR, Martinez D, Abi-Dargham A, Zea-Ponce Y, Simpson HB, Liebowitz MR, Laruelle M (2008) Striatal dopamine $\mathrm{D}_{2}$ receptor availability in OCD with and without comorbid social anxiety disorder: preliminary findings. Depress Anxiety 25:1-7.

Schneier FR, Abi-Dargham A, Martinez D, Slifstein M, Hwang DR, Liebowitz
MR, Laruelle M (2009) Dopamine transporters, D2 receptors, and dopamine release in generalized social anxiety disorder. Depress Anxiety 26:411-418.

Sharp BM (2017) Basolateral amygdala and stress-induced hyperexcitability affect motivated behaviors and addiction. Transl Psychiatry 7:e1194.

Shin LM, Liberzon I (2010) The neurocircuitry of fear, stress, and anxiety disorders. Neuropsychopharmacology 35:169-191.

Spielberger CD, Gorsuch RL, Lushene R, Vagg PR, Jacobs GA (1983) Manual for the State-Trait Anxiety Inventory. Palo Alto, CA: Consulting Psychologists.

Stevens JS, Jovanovic T, Fani N, Ely TD, Glover EM, Bradley B, Ressler KJ (2013) Disrupted amygdala-prefrontal functional connectivity in civilian women with posttraumatic stress disorder. J Psychiatr Res 47:1469-1478.

Stokes PR, Egerton A, Watson B, Reid A, Breen G, Lingford-Hughes A, Nutt DJ, Mehta MA (2010) Significant decreases in frontal and temporal $\left[{ }^{11} \mathrm{C}\right]-$ raclopride binding after THC challenge. Neuroimage 52:1521-1527.

Sturm V, Lenartz D, Koulousakis A, Treuer H, Herholz K, Klein JC, Klosterkötter J (2003) The nucleus accumbens: a target for deep brain stimulation in obsessive-compulsive- and anxiety-disorders. J Chem Neuroanat 26:293-299.

Takahashi H, Yahata N, Koeda M, Takano A, Asai K, Suhara T, Okubo Y (2005) Effects of dopaminergic and serotonergic manipulation on emotional processing: a pharmacological fMRI study. Neuroimage 27: 991-1001.

Taylor DP, Riblet LA, Stanton HC, Eison AS, Eison MS, Temple DL Jr (1982) Dopamine and antianxiety activity. Pharmacol Biochem Behav 17:25-35.

Tessitore A, Hariri AR, Fera F, Smith WG, Chase TN, Hyde TM, Weinberger DR, Mattay VS (2002) Dopamine modulates the response of the human amygdala: a study in Parkinson's disease. J Neurosci 22:9099-9103.

Thanarajah SE, Backes H, DiFeliceantonio AG, Albus K, Cremer AL, Hanssen R, Lippert RN, Cornely OA, Small DM, Bruning JC, Tittgemeyer M (2018) Food intake recruits orosensory and post-ingestive dopaminergic circuits to affect eating desire. Cell Metab. Advance online publication. Retrieved February 13, 2019. doi: 10.1016/j.cmet.2018.12.006.

Tiihonen J, Kuikka J, Bergström K, Lepola U, Koponen H, Leinonen E (1997) Dopamine reuptake site densities in patients with social phobia. Am J Psychiatry 154:239-242.

Tsukada H, Nishiyama S, Kakiuchi T, Ohba H, Sato K, Harada N (1999) Is synaptic dopamine concentration the exclusive factor which alters the in vivo binding of $\left[{ }^{11} \mathrm{C}\right]$ raclopride? PET studies combined with microdialysis in conscious monkeys. Brain Res 841:160-169.

Usala PD, Hertzog C (1991) Evidence of differential stability of state and trait anxiety in adults. J Pers Soc Psychol 60:471-479.

van der Wee NJ, van Veen JF, Stevens H, van Vliet IM, van Rijk PP, Westenberg HG (2008) Increased serotonin and dopamine transporter binding in psychotropic medication-naive patients with generalized social anxiety disorder shown by ${ }^{123} \mathrm{I}-\beta$-(4-iodophenyl)-tropane SPECT. J Nucl Med 49:757-763

Vijayraghavan S, Wang M, Birnbaum SG, Williams GV, Arnsten AF (2007) Inverted-U dopamine $\mathrm{D} 1$ receptor actions on prefrontal neurons engaged in working memory. Nat Neurosci 10:376-384.

Volkow ND, Wang GJ, Fowler JS, Logan J, Schlyer D, Hitzemann R, Lieberman J, Angrist B, Pappas N, MacGregor R (1994) Imaging endogenous dopamine competition with $\left[{ }^{11} \mathrm{C}\right]$ raclopride in the human brain. Synapse $16: 255-262$.

Volkow ND, Wang GJ, Fowler JS, Logan J, Franceschi D, Maynard L, Ding YS, Gatley SJ, Gifford A, Zhu W, Swanson JM (2002) Relationship between blockade of dopamine transporters by oral methylphenidate and the increases in extracellular dopamine: therapeutic implications. Synapse 43:181-187.

Volkow ND, Wang GJ, Telang F, Fowler JS, Alexoff D, Logan J, Jayne M, Wong C, Tomasi D (2014) Decreased dopamine brain reactivity in marijuana abusers is associated with negative emotionality and addiction severity. Proc Natl Acad Sci U S A 111:E3149-E3156.

Walsh K, Bennett G (2001) Parkinson's disease and anxiety. Postgrad Med J 77:89-93.

Yarkoni T, Poldrack RA, Nichols TE, Van Essen DC, Wager TD (2011) Large-scale automated synthesis of human functional neuroimaging data. Nat Methods 8:665-670.

Zilverstand A, Parvaz MA, Goldstein RZ (2017) Neuroimaging cognitive reappraisal in clinical populations to define neural targets for enhancing emotion regulation: a systematic review. Neuroimage 151:105-116. 